\title{
Factors affecting food choice in Greek primary-school students: ELPYDES study
}

\author{
Grigoris Risvas ${ }^{1}$, Demosthenes B Panagiotakos ${ }^{1}$ and Antonis Zampelas ${ }^{2, *}$ \\ ${ }^{1}$ Department of Nutrition and Dietetics, Harokopio University, Athens, Greece: ${ }^{2}$ Unit of Human Nutrition, \\ Department of Food Science and Technology, Agricultural University of Athens, lera Odos 75, \\ Athens 11855, Greece
}

Submitted 6 March 2007: Accepted 23 July 2007: First published online 15 0ctober 2007

\begin{abstract}
Objective: To measure factors affecting food choice in a sample of Greek schoolchildren attending 5 th and 6 th grade.

Design: Three self-administered questionnaires were distributed to the participants - one on nutritional knowledge, one on self-efficacy and social support for dietary change and a food-frequency questionnaire.

Setting: One hundred Greek primary schools from Attica and Thessaloniki regions.

Subjects: In total, 2439 students in 5th and 6th grades.

Results: Principal components analysis was applied to extract the main factors affecting food choice of our subjects. Six components were derived explaining $66 \%$ of the total variation in factors affecting food choice. The first component was characterised by readiness to make the healthier choice when competitive foods are considered (explained variation 29\%); the second was characterised by the impact of parents, friends and advertisements on students' choices and also the impact of taste, smell and cooking method on the consumption of vegetables (explained variation 11\%); the third component was characterised by readiness to choose fresh foods instead of ready-to-eat, pre-packaged choices as a main meal and awareness of the health value of fruits and vegetables (explained variation $8 \%$ ); the other components mainly expressed the interdependence of the main factors.

Conclusions: Nutrition education and health promotion programs in Greece must include family members and activities regarding food preparation, as well as education and environmental changes in schools. Public health measures must include regulation of advertising. Moreover, the categorisation of foods as 'healthier but less tasty' and 'appealing but unhealthy' needs to be challenged in the future, since balanced nutrition is founded in variety and norm.
\end{abstract}

Keywords
Food choice
Students
Greece

Food choice is a complex human behaviour that is affected by many interdependent factors. It is neither fully determined by the physiological and nutritional needs of a person nor from the perceptions and interest of a person in the health effects of certain foods and diets. Food choice depends on a group of factors ranging from biological mechanisms and genetic predisposition at one end of the scale to social and cultural factors at the other ${ }^{1}$.

The organoleptic characteristics of a food such as smell, taste, appearance and texture can play an important role in food choice. Nevertheless, the existence of such characteristics does not necessarily drive the consumption of a food. The way a person perceives these characteristics is the final path that will lead to the food's intake ${ }^{2}$. In addition, there are psychological parameters, such as personality, that may intervene in this path. Besides internal or food-related factors, there are many more, external, factors that affect food choice. These factors include marketing and promotion techniques and price, as well as sociodemographic and cultural impacts on dietary habits ${ }^{1}$.

Food choice in Greek students has been reported in the past as following a Westernised model far from the Mediterranean diet. $\mathrm{Cruz}^{3}$ reports that children in South Europe, including Greece, consume three or four meals per day, while a small percentage skips breakfast (not more than 15\%). However, they consume large amounts of foods rich in sugar and fat, and added sugar provides more than $10 \%$ of daily energy intake. It was also observed $^{4}$ in Spain and Greece that dietary fat accounts for $40 \%$ of total energy intake, while saturated and monounsaturated fatty acids account for $13 \%$ and 
17-19\%, respectively, mainly due to the high consumption of olive oil. According to a more recent study ${ }^{5}$ in an adolescent population aged 11.5 years, 50\% and 30\% consume soft drinks and sweets/confectionery, respectively, on a daily basis. Girls have healthier food choices than boys, since they consume fruits and vegetables more often and foods rich in fat and sugar less frequently than boys. Consecutively, a 202\% rise in the prevalence of obesity has been observed in 12-year-old Cretan boys from 1982 to 2002. During this 20-year period there has also been a significant increase in total cholesterol and low-density lipoprotein cholesterol, which are risk factors for cardiovascular disease ${ }^{6}$.

Since food choice plays an important role in health and growth and because there are no published data regarding factors affecting food choice in Greece, the objective of the present study was to measure these factors in a large sample of Greek schoolchildren attending 5th and 6th grade.

\section{Methods}

\section{Sampling procedure}

The school was considered as the sampling unit. For the ELPYDES study, we randomly selected 100 primary schools and 4752 students from Attica and Thessaloniki regions, which are the two bigger regions of the country, stratified according to the geographical distribution of their population. In particular, schools and students included in the study sample were stratified as follows:

- 66 schools with 2982 students from Attica region;

- 34 schools with 1770 students from Thessaloniki region.

The students included in the sample lived mainly in urban areas (89.2\% vs. $10.8 \%$ from rural areas) of the two regions. More specifically, 1808 (42.7\%) students attended schools situated in the centre of Athens or Thessaloniki, 1520 (35.9\%) students attended schools situated in the lower-class west suburbs of the two cities, and 909 (21.4\%) lived in the middle- and upper-class east and south suburbs. Moreover, the sample consisted of 2313 students attending kindergarten through 4 th grade, while 2439 were 5 th and 6th grade students.

These schools were selected from a pool of school units where health education programmes were supported by the National Youth Institute of Greece, separated into two groups:

- 53 primary schools where programmes concerning 'nutrition and dietary habits' were underway or had been implemented in the past two years;

- 47 primary schools where programmes dealing with other issues were underway or had been implemented in the past two years.

\section{Questionnaires}

The tools of the ELPYDES study that were distributed to 5 th and 6th grade students (11-13 years old) were selfadministered questionnaires that evaluated: (1) nutritional knowledge; (2) self-efficacy and social support for dietary change; and (3) the frequency of intake of 15 food groups.

The time given to the subjects to respond was 40 minutes in total and advice from specialised nutritionists was given to either the teacher or the students, when required, prior to distribution of the questionnaires.

The Nutrition Knowledge Questionnaire included some demographic questions at the beginning regarding age, school and grade, sex, and nationality of parents and adults living with the student or caregivers. After that, there were 14 multiple-choice questions with two, three or four possible answers, of which only one was correct. The Nutrition Knowledge Questionnaire was based on a questionnaire used in the CATCH study (Child and Adolescent Trial for Cardiovascular Health) in the USA ${ }^{7}$; it was translated into Greek and back-translated into English by two different groups of experts, as was the case with all of the questionnaires used in the ELPYDES study. All questionnaires were modified for regional nutritional particularities by another group of experts in our institution.

The Self-efficacy and Social Support for Dietary Change Questionnaire was based on a questionnaire used by Parcel et $\mathrm{al}^{8}$, which consisted of a scale developed to evaluate self-efficacy of elementary-school students regarding nutrition issues (Child Dietary Self-Efficacy Scale; CDSS).

Using a similar methodology, we tried to evaluate our subjects' intention to change. Our questionnaire included 20 questions that evaluated the perceived ability of students to choose certain products low in fat, sugar and salt instead of foods high in these ingredients and 10 questions that evaluated their perception on the support they would have when trying to make these choices. All of these questions started with the phrase 'How sure are you that...' and continued with the behaviour of the student or the perceived behaviour of a 'significant other' we were examining. The answers were given in a Likert-type scale that was numbered from 1 to 5 , where $1=$ not at all sure, $2=$ a little sure, $3=$ sure enough, $4=$ very sure and $5=$ extremely sure that the subject can do what the question asks or that the subject's parents/friends will do what the question asks. Subjects were expected to circle the number that stated their level of confidence.

Questions focused mainly on consumption of fruits, vegetables, sweets/confectionery and carbonated soft drinks; factors that affect students' dietary behaviour such as family, peers, television and marketing; organoleptic characteristics (smell, taste) of foods; and cost. As mentioned above, we took under consideration the regional nutritional particularities of the Greek sample and we performed repeatability tests using a test-retest procedure. In particular, we administered the questionnaires 
twice to a subgroup of our sample with an interval of 3 weeks. We then performed a Wilcoxon signed ranks test and observed that the $P$-value was larger than 0.5 , concluding that the questionnaire was repeatable. The reliability of the questionnaire was also measured using Cronbach's alpha statistic and found to be very satisfactory $(\alpha=0.81)$.

We also used a simple food-frequency questionnaire (FFQ), which included 15 food groups corresponding to the food groups from the Mediterranean Diet Pyramid plus carbonated soft drinks. Thus, our FFQ included fresh fruits, vegetables, red meat, chicken, fish, milk/cheese/ yoghurt, cereals/bread/pasta, potatoes, olive oil, other oils and fats, legumes, nuts, eggs, sweets and carbonated soft drinks; and seven frequency categories for responses, namely 4-6 times/day, 1-3 times/day, 5-6 times/week, 2-4 times/week, 1 time/week, 1-3 times/month and rarely or never. The reliability of the questionnaire was measured using Cronbach's alpha statistic and found to be satisfactory ( $\alpha=0.64)$, while its repeatability was tested and verified at an earlier stage in a sub-sample of 50 elementary-school students from 5th and 6th grade. Although there is consensus among nutrition researchers that the FFQ is the least preferred method to assess diet, unless it is used in combination with another more accurate method like multiple 24-hour dietary recalls, this is true only as far as nutrient intake assessment is concerned. Use of the FFQ to evaluate food group preferences is considered a very adequate method ${ }^{9}$ and the FFQ is also used for the development of diet indices for the assessment of diet quality ${ }^{10}$. This was our main goal of this project and not evaluation of the nutrient intake of participating students.

\section{Statistical analyses}

For description of the results we used frequencies (and percentages) for categorical variables, and mean \pm standard deviation or median (range) for continuous or ordinal variables, respectively. Normality tests were performed using the Kolmogorov-Smirnov criterion. Tests for differences in mean values of continuous variables between two groups were performed with Student's $t$-test (for normally distributed variables) or the Mann-Whitney $U$-test (for discrete or skewed variables). Tests for mean differences in continuous or ordinal variables between more than two groups were performed with analysis of variance or the Kruskal-Wallis test, respectively. Tests for differences in percentages between two or more groups were performed with the $Z$-statistic. In order to evaluate potential correlations between continuous or ordinal variables and to reduce the dimensions of the initial information, we performed a multivariate technique, principal components analysis (PCA). It is known that in order for the results from PCA to have some value, strong correlations between the variables should exist; the correlation matrix of the variables used in the present analysis showed that there were several correlation coefficients $|r|>0.2$, indicating that the variables were correlated with one another and, therefore, that PCA could be effective for assessing various patterns. The selection of the number of principal components was based on the percentage of total variance explained (i.e. $>60 \%$ ) and Cattell's scree test. We performed PCA on the variables that evaluated the perceived ability of students to choose certain foods (PCA1) and the variables that evaluated their perception on the support they would have when trying to make these choices (PCA2). Finally, we performed a combined PCA (PCA3) on the remaining components after the application of PCA1 and PCA2. All statistical tests were performed at a level of statistical significance of 0.01. Analyses were conducted using STATA 8 software (StataCorp.) and the pca procedure was used to perform the analysis. Orthogonal rotation (rotate with varimax option) was used to derive optimal noncorrelated components (i.e. patterns). The information was rotated in order to increase the representation of each food or food group to a component.

\section{Results}

We have included 2439 students from 5 th and 6th grade. The mean age of the study sample was $11.3 \pm 0.77$ years; $85 \%$ of the children were living with both parents, while $10 \%$ lived with just one parent. Ninety per cent of the sample was living in urban areas and almost half of those lived in the city centre. Some $40 \%$ of the students had not attended a nutrition-related health education programme. Concerning frequency of food group intake, girls consumed significantly more cereals/bread/pasta $(P=0.007)$ and nuts $(P=0.004)$ than boys, while differences in the consumption of potatoes, legumes, eggs and carbonated soft drinks were of borderline significance $(P<0.05)$, with girls generally reporting more frequent intakes of these food groups than boys.

\section{Principal components analysis}

PCA1 extracted four components that explained $41 \%$ of the total variation in self-efficacy for dietary change. The scores for the four self-efficacy components are presented in Table 1 (coefficients with absolute value $>0.2$ are shown in bold). Since higher absolute value indicates that the self-efficacy variable contributes more to the development of the component ${ }^{11}$, the following components were derived: Component 1 - readiness to make the healthier choice when competitive foods are considered, which loaded equally on all situations regarding fruits and vegetables against other competitive foods; Component 2 - readiness to choose fresh foods instead of ready-to-eat, pre-packaged choices as a main meal, but not ready to 
Table 1 Coefficients of the four principal components that remain in the analysis after applying principal components analysis on self-efficacy for dietary change (PCA1)

\begin{tabular}{|c|c|c|c|c|}
\hline \multirow[b]{2}{*}{ Question } & \multicolumn{4}{|c|}{ Component } \\
\hline & 1 & 2 & 3 & 4 \\
\hline Fresh instead of canned/frozen vegetables & 0.145 & 0.234 & -0.052 & 0.138 \\
\hline Fresh tomato sauce instead of ketchup in pasta & 0.187 & 0.363 & 0.077 & 0.341 \\
\hline Lettuce and tomato in sandwich instead of ketchup and mustard & 0.215 & 0.268 & -0.090 & 0.417 \\
\hline Carrot/cucumber instead of chips/oily or salty snacks & 0.261 & 0.049 & -0.268 & 0.276 \\
\hline Apple instead of doughnut & 0.254 & 0.128 & -0.259 & -0.058 \\
\hline Fresh juice instead of cola-type soft drink & 0.225 & 0.070 & -0.147 & -0.022 \\
\hline Cereals for breakfast instead of croissant & 0.151 & 0.122 & 0.051 & -0.082 \\
\hline Fruit-flavoured yoghurt instead of ice cream & 0.244 & -0.310 & -0.209 & 0.138 \\
\hline Orange instead of biscuit & 0.234 & -0.053 & -0.145 & -0.006 \\
\hline Less sugar in beverages & 0.212 & 0.078 & -0.241 & -0.445 \\
\hline Fruit gel instead of chocolate cake & 0.254 & -0.343 & -0.154 & -0.108 \\
\hline Home-made sandwich instead of pizza slice from school & 0.234 & 0.094 & -0.005 & -0.056 \\
\hline Fruit for dessert instead of sweet & 0.243 & -0.121 & -0.074 & -0.123 \\
\hline Gums without sugar instead of sugary gums & 0.214 & 0.154 & 0.297 & -0.203 \\
\hline Raisins for afternoon snack instead of chocolate & 0.256 & -0.450 & 0.039 & 0.265 \\
\hline Fresh peach instead of syrup-made peach compote & 0.199 & 0.251 & 0.146 & -0.394 \\
\hline Boiled or roasted corn instead of pop corn & 0.190 & 0.021 & 0.599 & 0.241 \\
\hline Whole-grain biscuits instead of chocolate bar & 0.239 & -0.245 & 0.373 & -0.112 \\
\hline Home-made marmalade instead of praline on bread & 0.262 & -0.166 & 0.244 & -0.094 \\
\hline Meat or fish with vegetable side dish instead of mustard or & 0.203 & 0.282 & -0.007 & -0.106 \\
\hline Percentage of explained variability & 0.25 & 0.06 & 0.05 & 0.05 \\
\hline Cumulative percentage of explained variability & 0.25 & 0.31 & 0.36 & 0.41 \\
\hline
\end{tabular}

Table 2 Coefficients of the five principal components that remain in the analysis after applying principal components analysis on social support for dietary change (PCA2)

\begin{tabular}{|c|c|c|c|c|c|}
\hline \multirow[b]{2}{*}{ Question } & \multicolumn{5}{|c|}{ Component } \\
\hline & 1 & 2 & 3 & 4 & 5 \\
\hline Parents wouldn't bring sweets such as chocolate and croissant home & 0.159 & 0.175 & 0.171 & -0.001 & 0.298 \\
\hline Parents would insist to consume salad with every meal & 0.137 & 0.468 & -0.008 & -0.352 & 0.065 \\
\hline Parents would insist to consume fresh fruits and juices regularly & 0.362 & -0.279 & 0.351 & 0.510 & 0.158 \\
\hline Buy fruits on your own & 0.151 & 0.680 & 0.309 & 0.437 & -0.281 \\
\hline Friends would affect you on choosing a snack during recess & 0.386 & -0.261 & 0.139 & 0.143 & 0.036 \\
\hline Eat fruits and vegetables for health reasons & 0.050 & 0.295 & -0.002 & -0.080 & -0.067 \\
\hline Taste and smell affect your choice of vegetables & 0.266 & 0.071 & -0.597 & 0.256 & 0.041 \\
\hline Cooking affects your choice of vegetables & 0.395 & 0.108 & -0.564 & 0.105 & 0.129 \\
\hline Parents would increase availability of freshly cut fruits at home & 0.474 & -0.191 & 0.051 & -0.332 & -0.746 \\
\hline TV advertisements for sweets such as chocolate and croissant wouldn't be broadcast often & 0.446 & 0.047 & 0.235 & -0.461 & 0.472 \\
\hline Percentage of explained variability & 0.18 & 0.13 & 0.12 & 0.10 & 0.10 \\
\hline Cumulative percentage of explained variability & 0.18 & 0.31 & 0.43 & 0.53 & 0.63 \\
\hline
\end{tabular}

avoid ice cream or chocolate as a dessert or snack; Component 3 - readiness to choose traditional foodstuffs instead of modern choices, excluding foods such as chips, doughnuts, ice creams and sugar-sweetened beverages; and Component 4 - preference for vegetables and sugar. Component 1 was the most dominant food choice factor and explained $25 \%$ of the total variance. Each of the remaining three components explained from 5\% (Components 3 and 4 ) to $6 \%$ (Component 2) of the variance in self-efficacy.

PCA2 extracted five components that explained 63\% of the total variation in social support for dietary change. The scores for the five social support components are presented in Table 2 (coefficients with absolute value $>0.2$ shown in bold). Since higher absolute value indicates that the social support variable contributes more to the development of the component ${ }^{11}$, the following components were derived: Component 1 - impact of parents, friends and advertisements on students' choices and also impact of taste, smell and cooking method on the consumption of vegetables by this age group; Component 2 - initiative to buy fruits and awareness of the health value of fruits and vegetables, together with impact of parents' advice on vegetable choice; Component 3 effect of external factors on the consumption of fruits and sweets; Component 4 - impact of parents' advice for fruits and preparation methods for vegetables on their consumption; and Component 5 - impact of parents' eating behaviour and preparation methods on fruit consumption and of advertisements on consumption of 
Table 3 Coefficients of the six principal components that remain in the analysis after applying principal components analysis for a second time on the four principal components that remained in the analysis after applying PCA1 and the five principal components that remained in the analysis after applying PCA2 (PCA3)

\begin{tabular}{|c|c|c|c|c|c|c|}
\hline & \multicolumn{6}{|c|}{ Component } \\
\hline & 1 & 2 & 3 & 4 & 5 & 6 \\
\hline Readiness to make the healthier choice & 0.9571 & -0.0906 & -0.0549 & -0.0815 & -0.2349 & 0.0251 \\
\hline $\begin{array}{l}\text { Readiness to choose fresh foods instead of ready-to- } \\
\text { eat, pre-packaged choices as a main meal, } \\
\text { but not ready to avoid ice cream or chocolate as a } \\
\text { dessert or snack }\end{array}$ & -0.0019 & -0.1738 & 0.6295 & 0.3606 & -0.0447 & 0.0008 \\
\hline $\begin{array}{l}\text { Readiness to choose traditional foodstuffs instead of } \\
\text { modern choices, excluding foods such as } \\
\text { chips, doughnuts, ice creams and sugar-sweetened } \\
\text { beverages }\end{array}$ & 0.0051 & -0.0347 & -0.0206 & 0.2664 & 0.1000 & 0.3150 \\
\hline Preference for vegetables and sugar & -0.0005 & 0.0715 & -0.0468 & -0.0634 & 0.0067 & 0.1902 \\
\hline $\begin{array}{l}\text { Impact of parents, friends and advertisements on } \\
\text { students' choices and also impact of taste, smell and } \\
\text { cooking method on the consumption of vegetables by } \\
\text { this age group }\end{array}$ & 0.1527 & 0.9415 & 0.1946 & 0.0835 & 0.1569 & -0.0412 \\
\hline $\begin{array}{l}\text { Initiative to buy fruits and awareness of the health value } \\
\text { of fruits and vegetables, together with impact of } \\
\text { parents' advice on vegetable choice }\end{array}$ & 0.2335 & -0.2432 & 0.3130 & 0.0640 & 0.7765 & -0.0588 \\
\hline $\begin{array}{l}\text { Effect of external factors on the consumption of fruits } \\
\text { and sweets }\end{array}$ & 0.0756 & -0.0070 & -0.6681 & 0.4976 & 0.3149 & -0.1362 \\
\hline $\begin{array}{l}\text { Impact of parents' advice for fruits and preparation } \\
\text { methods for vegetables on their consumption }\end{array}$ & -0.0148 & 0.0128 & -0.1101 & -0.6827 & 0.4165 & 0.1262 \\
\hline $\begin{array}{l}\text { Impact of parents' eating behaviour and preparation } \\
\text { methods on fruit consumption and of advertisements } \\
\text { on consumption of sweets }\end{array}$ & 0.0074 & 0.0119 & -0.0292 & 0.0743 & 0.0107 & 0.8927 \\
\hline Percentage of explained variability & 0.29 & 0.11 & 0.08 & 0.06 & 0.06 & 0.06 \\
\hline Cumulative percentage of explained variability & 0.29 & 0.40 & 0.48 & 0.54 & 0.60 & 0.66 \\
\hline
\end{tabular}

sweets. Component 1 was the most dominant food choice factor and explained 18\% of the total variance. Each of the remaining four components explained from 13\% (Component 2) to $10 \%$ (Components 4 and 5) of the variance in social support.

PCA3 extracted six components that explained 66\% of the total variation in factors affecting dietary change. The scores for the six factors components are presented in Table 3 (coefficients with absolute value $>0.2$ shown in bold). Since higher absolute value indicates that the factor variable contributes more to the development of the component $^{11}$, the following components were derived: Component 1 - readiness to make the healthier choice when competitive foods are considered; Component 2 impact of parents, friends and advertisements on students' choices and also impact of taste, smell and cooking method on the consumption of vegetables by this age group; Component 3 - readiness to choose fresh foods instead of ready-to-eat, pre-packaged choices as a main meal and awareness of the health value of fruits and vegetables; Component 4 - tendency to consume fresh fruits and vegetables as a result of the impact parents have on students' choices (vegetable choice was the only one affected by an external factor, namely parents' advice); Component 5 - overall effect of social support in food choice; and Component 6 - impact of parents' eating behaviour and preparation methods on fruit consumption and of advertisements on consumption of sweets. Com- ponent 1 was the most dominant food choice factor and explained $29 \%$ of the total variance. Each of the remaining five components explained from 11\% (Component 2) to $6 \%$ (Components 4,5 and 6) of the variance in factors affecting dietary change.

\section{Discussion}

Factors affecting the dietary behaviour of children and adolescents have been thoroughly examined and reviewed during the past decade. In our sample we have observed six principal components that drive food choice. Three of them accounted for $48 \%$ of the total variation in factors affecting food choice, namely: (1) readiness to make the healthier choice when competitive foods are considered; (2) impact of 'significant others' (parents, friends and advertisements) on students' choices and also impact of taste, smell and cooking method on the consumption of vegetables; and (3) readiness to choose fresh foods instead of ready-to-eat, pre-packaged choices as a main meal and awareness of the health value of fruits and vegetables.

The first component showed a tendency of students to categorise foods into two groups: the 'healthier' fruits, vegetables and home-made snacks group and the competitive group where snacks rich in sugar, fat and salt were included. The notion of two competitive groups of 
foods has been widely used in nutrition policy primarily in the USA. The American Dietetic Association has recently published ${ }^{12}$ a new position statement renewing its commitment on Nutrition Integrity in Schools, where it refers explicitly to a level of performance that assures all foods and beverages available in schools are consistent with the Dietary Guidelines for Americans. Therefore, competitive foods in schools must reach a similar level of nutritional adequacy and quality as the one characterising 'healthy choices'. Since the students in our sample tend to categorise their choices in two groups, following such an approach with competitive foods could be most successful.

The second component deals with external factors determining choice of fruits, vegetables, school snacks and confectionery. More specifically, it expresses the impact of parents, friends and advertisements on students' choices and the impact of taste and smell on the consumption of vegetables by this age group. Parents play a very important role in shaping children's eating behaviour from an early age. The control they have over the quality and quantity of foods served to their offspring can modulate children's choice of food at a later age. For example, it is very common on the parents' side to limit the availability of sweets, such as chocolate and candies, at home. However, this confinement works in reverse and makes these foods, which are competitive to fruits and vegetables, more appealing to children ${ }^{13}$. Thus they are more likely to be consumed on occasions when parents are not present. This is true for our sample too, since students reported that they were not ready to avoid ice cream or chocolate as a dessert or snack.

In addition, using foods as a reward or punishment is a tactic usually adopted by parents when trying to persuade their children to behave in a certain way. Whether it is to eat their meal or study their lessons or go to bed early, this tactic always drives a categorisation of foods as 'good' or 'bad', where 'bad' foods are consumed only on pleasant occasions (such as a party) or as a reward after eating a 'good' food (e.g. 'if you eat your legumes you can then have the ice cream you are asking for'). This habit creates confusion in the messages children receive, since 'good' foods such as vegetables are only chosen obligatorily, because the parents say so, and thus play the role of a punishment to disobedient children ${ }^{14}$. Again, ice cream and chocolate are typical rewards to children and this is why they report not being able to avoid them or choose an alternative nutritious choice.

Nevertheless, parents can play an important role in guiding their children's food choices by acting as a role model for balanced nutrition through their beliefs and daily habits. Availability of fruits and vegetables at home is a primary target through which they can affect their children's choices ${ }^{2}$ and our observations support these results since parents' impact on students' consumption of fruits was mainly driven by availability of freshly cut fruits at home. According to Social Cognitive Theory, 'significant others' constitute an integral part of the influence of the external environment, through learning by observation and role modelling. Brown and Ogden ${ }^{15}$ found a strong positive relationship between parents' and primary-school students' consumption of healthy and competitive snacks.

However, the magnitude of the effect of parents and family diminishes during adolescence ${ }^{16}$. Our sample of preadolescent students was characterised by a balanced effect between parents and peers, where parents affected food choice at home and peers affected it at recess. Patterson et al. ${ }^{17}$ found that the correlation coefficient for nutrient intakes between parents and children was smaller at the age of 13 years than at age 11. After parents, friends and peers are the main modulators of eating habits. Peers seem to overwhelm the effect of teachers or other adults mainly in girls ${ }^{18}$. Hendy reported that specially trained peers were successful in acting as role models for the acceptance of new foods, such as vegetables, in their schoolmates' diets ${ }^{19}$. These results, however, did not stand for more than one month and concerned only school meals. Thus, although using peer pressure could be a successful policy to change dietary habits in school, there is another factor affecting adolescents' food choices outside the school environment that needs to be addressed.

The single strongest factor affecting children's food choice on the societal level is television advertising. As we observed too, students stated that they would consume less sweets and confectionery 'if relevant TV advertisements wouldn't be broadcast often'. Children watch television from a very young age, resulting in them receiving messages regarding nutrition mainly from advertisements. These messages concern the acceptance and consumption of certain foods, as well as the adoption of a certain dietary behaviour. Most advertised foods are rich in fat and sugar and poor in fibre ${ }^{20}$. These foods constitute the main food choices of children and create a dietary pattern that is very difficult to change later in life ${ }^{2}$. In a sample of 4211 students in Greece, Yannakoulia et $a l^{5}$ reported that television viewing was associated with the consumption of selected food items. In particular, the more hours spent in front of the television, the higher the percentage of students reporting to consume sodas (from 28.6 to $68.6 \%$ ), crisps (from 15.7 to $43.4 \%$ ), cakes and pastries (from 8.6 to $25.9 \%$ ) and sweets and chocolates (from 31.5 to $52.5 \%$ ) at least once a day, whereas the less frequent the consumption of fruits (from 92.8 to $76.3 \%$ ).

Besides the impact parents, friends and television advertising have in students' food choices, there is always the element of taste that forms the acceptance of certain foods and mainly vegetables, as was the case in our sample too. According to youngsters, they consume a food because they believe it is tasteful, appealing and 
convenient $^{21}$. In addition, they do not believe that the 'healthy' nature of a food is relevant to their needs, while they confess that the healthfulness of a food is not promoted among their peers or the societies in which they live and eat. Therefore, the fact that the second most prominent component, explaining $11 \%$ of the variability in our sample, included the aforementioned factors coincides with data from similar populations in other developed countries, besides Greece. Moreover, the cumulative percentage of $40 \%$ of the total variability being explained by the first two components, where the notion of competitive foods is added to external factors and taste, shows that the main public health goals, when trying to improve students' dietary habits, must regard both family and friends, regulate television advertising and try to present all foods as appealing and tasteful as the ones rich in fat and sugar.

The third component incorporates the notion of freshness, which is typical and unique of the Greek culture. This is the reason why there are no such references in other studies investigating food choice. Owing to the tradition of the Mediterranean diet, which is promoted in schools through health education programmes and taught curriculum, Greek students and their parents have a tendency to regard anything fresh and traditional as being the healthier choice. Thus the third most important component, explaining $8 \%$ of the total variability, practically discriminated foods in two categories according to their place in the Mediterranean Diet Pyramid. As far as the remaining components are concerned, they expressed the interdependence of factors already mentioned herein, which can work in different ways and combinations, since we have not yet fully understood and described a mechanism for food choice.

An important limitation of our study is that we did not manage to collect data from all regions of Greece, where we would probably be able to discern factors affecting food choice in semi-urban and rural areas. However, Athens and Thessalloniki are the two largest cities in Greece and along with their suburbs they host $60-65 \%$ of the total population of the country. Moreover, the schools included in the study sample were schools where health education programmes have been undertaken, in order to obtain the permission and support of the head teachers to perform the study. However, the stratification of schools among the geographic regions of Attica and Thessaloniki was representative of the population's sociodemographic characteristics.

The questionnaires regarding self-efficacy and social support were distributed only to 5th and 6th grade students, because the pre-testing showed that they would be difficult for younger students to fill in. Another limitation is that we did not use other tools for dietary evaluation (such as 24-hour recall) in addition to the FFQ; however, we believe that this fact did not influence our findings regarding food group choices of the students.

\section{Conclusion}

In conclusion, food choice in a large sample of Greek primary-school children is affected mainly by parents, peers, television advertising, and the taste and appearance of dishes. Therefore nutrition education and health promotion programmes in Greece must include family members and activities regarding food preparation, besides education and environmental changes in schools. Moreover, regulation of advertising is an important public health measure that needs to be discussed in Greece, as it is already being discussed in the European Union and the USA. Finally, Greek students have learnt to categorise foods as 'healthier (more traditional and fresh) but less tasty' and 'appealing but unhealthy'. This is a notion that needs to be challenged in the future, since balanced nutrition is founded in variety and norm.

\section{Acknowledgements}

This paper was supported by the Iraklitos Program 'Research Scholarships in Harokopio University' cofunded by the European Union and the Greek Ministry of Education. The authors would like to acknowledge the contribution of Ms Konstantina Karasouli and Ms Stavroula Chrysanthopoulou in the data collection and data handling processes, respectively.

\section{References}

1 Shepherd R. Social determinants of food choice. Proceedings of the Nutrition Society 1999; 58: 807-12.

2 Birch LL, Fisher JO. Development of eating behaviors among children and adolescents. Pediatrics 1998; 101: 539-49.

3 Cruz JA. Dietary habits and nutritional status in adolescents over Europe - Southern Europe. European Journal of Clinical Nutrition 2000; 54: S29-35.

4 Roma-Giannikou E, Adamidis D, Gianniou M, Nikolara R, Matsaniotis N. Nutritional survey in Greek children: nutrient intake. European Journal of Clinical Nutrition 1997; 51 : 273-85.

5 Yannakoulia M, Karayiannis D, Terzidou M, Kokkevi, Sidossis LS. Nutrition-related habits of Greek adolescents. European Journal of Clinical Nutrition 2004; 58: 580-6.

6 Magkos F, Manios Y, Christakis G, Kafatos A. Secular trends in cardiovascular risk factors among school-aged boys from Crete, Greece, 1982-2002. European Journal of Clinical Nutrition 2005; 59: 1-7.

7 Perry CL, Baranowski T, Parcel GS. How individuals, environments, and health behavior interact: Social Learning Theory. In: Glansk K, Lewis FM, Rimer BK, eds. Health Behavior and Health Education: Theory, Research and Practice. San Francisco, CA: Jossey-Bass, 1990; 161-86.

8 Parcel G, Edmundson E, Perry C, Feldman H, O'HaraTompkins N, Nader P, et al. Measurement of self-efficacy for diet-related behaviors among elementary school children. Journal of School Health 1995; 65: 23-7.

9 Willett W. Nutritional Epidemiology. New York: Oxford University Press, 1990.

10 Kant AK. Indexes of overall diet quality: a review. Journal of the American Dietetic Association 1996; 96: 785-91. 
11 Mardia KV, Kent JT, Bibby JM. Multivariate Analysis, 1st ed. New York: Academic Press, 1979.

12 Position of the American Dietetic Association: local support for nutrition integrity in schools. Journal of the American Dietetic Association 2006; 106: 122-33.

13 Hill AJ. Developmental issues in attitudes to food and diet. Proceedings of the Nutrition Society 2002; 61: 259-66.

14 Birch LL. Development of food preferences. Annual Review of Nutrition 1999; 19: 41-62.

15 Brown R, Ogden J. Children's eating attitudes and behavior: a study of the modeling and control theories of parental influence. Health Education Research 2004; 19: 261-71.

16 Cheung LWY, Richmond JB. Child Health Nutrition. Champaign, IL: Human Kinetics, 1995.

17 Patterson TL, Rupp J, Sallis J, Atkins C, Nader PR. Aggregation of dietary calories, fats, and sodium in Mexican
American and Anglo families. American Journal of Preventive Medicine 1988; 4: 75-82.

18 Hendy H, Raudenbush B. Effectiveness of teacher modeling to encourage food acceptance in preschool children. Appetite 2000; 34: 61-76.

19 Hendy $H$. Effectiveness of trained peer models to encourage food acceptance in preschool children. Appetite 2002; 39: $217-25$.

20 Kotz K, Story M. Food advertisements during children's Saturday morning television programming: are they consistent with dietary recommendations? Journal of the American Dietetic Association 1994; 94: 1296-300.

21 Neumark-Sztainer D, Story M, Perry C, Casey MA. Factors influencing food choices of adolescents: findings from focus-group discussions with adolescents. Journal of the American Dietetic Association 1999; 99: 929-37. 